\title{
PERGESERAN PARADIGMA PEMBELAJARAN PADA PENDIDIKAN TINGGI
}

\author{
Dian Rahadian \\ Pend. Teknologi Informasi STKIP GARUT \\ dian.rahadian@yahoo.com
}

\begin{abstract}
ABSTRAK. --- Terdapat tiga fungsi pendidikan tinggi menurut Undang-undang no.12 pasal 4 tahun 2012 tentang pendidikan tinggi, yaitu (1) Mengembangkan kemampuan dan membentuk watak serta peradaban bangsa yang bermartabat dalam rangka mencerdaskan kehidupan bangsa; (2) Mengembangkan Sivitas Akademika yang inovatif, responsif, kreatif, terampil, berdaya saing, dan kooperatif melalui pelaksanaan Tridharma; dan (3) Mengembangkan Ilmu Pengetahuan dan Teknologi dengan memperhatikan dan menerapkan nilai Humaniora. Untuk menjalankan ketiga fungsi tersebut di atas, perguruan tinggi harus mampu menyelenggarakan pembelajaran yang sangat mendukung terhadap pengembangan potensi setiap peserta didik dan pengajaran yang efektif. Perubahan paradigma pembelajaran terjadi dari paradigma berfokus pada guru/dosen menjadi pembelajaran berfokus pada peserta didik atau mahasiswa. Pada pendidikan tinggi dikenal Student-Centered Learning sebagai pembelajaran yang berfokus pada mahasiswa. Keterpaduan lembaga pendidikan dalam menghasilkan pembelajaran yang berkualitas yang dilakukan oleh dosen dan mahasiswa menjadi bentuk yang utuh dalam pendekatan ini.
\end{abstract}

Kata Kunci: Paradigma Pembelajaran, Pendidikan Tinggi.

\section{A. RASIONAL}

Memaknai pembelajaran merupakan upaya yang dilakukan oleh setiap orang sejak ribuan tahun yang lalu. Banyak orang yang menganggap belajar adalah membaca dan menghapal. Hammond, Austin, Orcutt, dan Rosso (2001:3) mengatakan bahwa "Many classrooms today continue a transmission-based conception of learning as the passing on of information from the teacher to the student, with little interest in transforming it or using it for novel purposes". Kenyataannya bahwa pada saat ini banyak pembelajaran yang dilakukan di ruang kelas dengan hanya melanjutkan konsep pembelajaran berbasis tranmisi. Artinya, pembelajaran dilaksanakan hanya untuk menyampaikan informasi dari guru kepada siswanya dan hanya sedikit pula upaya yang dilakukan untuk menggunakan informasi tersebut untuk tujuan yang baru. Tapscott (2009:122) mengkritisinya dengan mengatakan "...the education system in many places is lagging at least 100 years behind. The model of education that still prevails today was designed for the Industrial Age. It revolves around the teacher who delivers a one-size-fits-all, one-way lecture. The student, working alone, is expected to absorb the content delivered by the teacher". Kritikan tersebut menegaskan bahwa pembelajaran yang dilakukan dalam upaya pendidikan harus sesuai dengan perkembangan jaman. Seorang dosen tidak bisa melakukan satu cara mengajar yang berlaku bagi seluruh mahasiswanya dengan perkuliahan satu arah serta mengharapkan para mahasiswa untuk memahami materi dan mampu mengerjakan tugas sendiri.

Penyelenggaraan pendidikan dimaksudkan untuk membantu manusia menjadikan dirinya sebagaimana mestinya sesuai dengan yang mereka mampu, dan para pendidik harus mampu memahami mereka dalam aktualitas, kemungkinankemungkinan dan idealitasnya serta para pendidik harus tahu bagaimana menumbuhkan perubahan-perubahan yang diinginkan oleh mereka (Phenix, 1986:17). Ki Hajar Dewantara (dalam Majelis Luhur Persatuan Taman Siswa, 2004:14) memandang pendidikan sebagai daya upaya untuk memajukan bertumbuhnya budi pekerti (kekuatan batin, karakter), pikiran (intellect) dan tubuh anak. Dan, tujuan pendidikan nasional sebagaimana yang tercantum dalam Undang-undang nomor 20 tahun 2003 adalah berkembangnya potensi peserta didik agar menjadi manusia yang beriman dan bertakwa kepada Tuhan Yang Maha Esa, berakhlak mulia, sehat, berilmu, cakap, kreatif, mandiri, dan menjadi warga negara yang demokratis serta bertanggung jawab.

Terdapat tiga fungsi pendidikan tinggi menurut Undang-undang no.12 pasal 4 tahun 2012 tentang pendidikan tinggi, yaitu:

1. Mengembangkan kemampuan dan membentuk watak serta peradaban bangsa yang bermartabat dalam rangka mencerdaskan kehidupan bangsa;

2. Mengembangkan Sivitas Akademika yang inovatif, responsif, kreatif, terampil, berdaya saing, dan kooperatif melalui pelaksanaan Tridharma; dan

3. Mengembangkan Ilmu Pengetahuan dan Teknologi dengan memperhatikan dan menerapkan nilai Humaniora. Untuk menjalankan ketiga fungsi tersebut di atas, perguruan tinggi harus mampu menyelenggarakan pembelajaran yang sangat mendukung terhadap pengembangan potensi setiap peserta didik dan pengajaran yang efektif. Bahkan, dalam tantangan globalisasi, Jarvis (Report on the Preparatory Meeting for the World Conference on Higher Education, 1998:32) menegaskan bahwa "...universities need to adapt rapidly to the new demands being placed upon them by the new groups of mature students emerging as a result of these trends in order to retain their position of the major providers of high level learning opportunities". Adaptabilitas perguruan tinggi dengan tuntutan-tuntutan yang dihadapi oleh para peserta didik dalam meningkatkan kapabilitasnya adalah suatu keharusan. Kecenderungan-kecenderungan dalam pembelajaran orang 
dewasa (pendidikan tinggi), Jarvis (2001) memandang bahwa "the relationship between work and education is part of the dominant discourse at the present time".

Kegiatan pembelajaran sebagai implementasi dari tujuan tersebut harus mampu menciptakan kesempatan dan peluang bagi para peserta didik untuk mengembangkan kompetensi global. Dimana, elemen utama kompetensi global antara lain "...habits of the mind that embrace tolerance, a commitment to cooperation, an appreciation of our common humanity, and a sense of responsibility" (NEA,2010). Urgensi kualitas pengajaran dan pembelajaran pada pendidikan tinggi menjadi sangat penting untuk menghasilkan para lulusan yang mampu beradaptasi, kreatif dan berfikir kritis untuk membangun masa depannya.

Dalam pembaharuan sistem pendidikan nasional telah ditetapkan visi, misi, dan strategi pembangunan pendidikan nasional. Visi pendidikan nasional adalah terwujutnya sistem pendidikan sebagai pranata sosial yang kuat dan berwibawa untuk memberdayakan semua Warga Negara Indonesia, berkembang menjadi manusia yang berkualitas sehingga mampu dan proaktif menjawab tantangan zaman yang selalu berubah. Terkait dengan visi tersebut, telah ditetapkan serangkaian prinsip yang dijadikan landasan dalam pelaksanaan reformasi pendidikan.

Salah satu prinsip tersebut adalah bahwa pendidikan diselenggarakan sebagai proses pembudayaan dan pemberdayaan peserta didik yang berlangsung sepanjang hayat. Dalam proses tersebut harus ada pendidik yang memberikan keteladanan dan mampu membangun kemauan, serta mengembangkan potensi dan kreativitas peserta didik. Prinsip tersebut menyebabkan adanya pergeseran paradigma proses pendidikan, dari paradigma pengajaran ke paradigma pembelajaran. Kampus tidak lagi berperan sebagai penyedia pengajaran melainkan sebagai penghasil pembelajaran.

\section{B. PEMBELAJARAN ORANG DEWASA}

Pelaksanaan pembelajaran di Perguruan Tinggi tentunya harus berbeda dengan pendidikan menengah dan dasar. Peserta didik pada perguruan tinggi adalah orang dewasa dengan kompleksitasnya sebagai manusia. Terdapat empat asumsi yang melandasi teori pendidikan bagi orang dewasa, menurut Knowles dalam Andragogical Theory (1973:45), antara lain adalah "(1) Changes in self-concept, (2) the role of experience, (3) readiness to learn, and (4) orientation to learning". Asumsi changes in self-concept diartikan sebagai " $a$ person grows and matures his self-concept moves from one of total dependency (as is the reality of the infant) to one of increasing self directedness".

Asumsi perubahan pada konsep diri (Changes in SelfConcept) adalah bahwa sebagai pribadi yang tumbuh dan dewasa konsep dirinya bergerak dari seseorang yang penuh ketergantungan menjadi seseorang yang meningkatkan otoritas dirinya dan secara psikologi ia menjadi dewasa. Pada kondisi ini, muncul kebutuhan psikologisnya untuk dianggap oleh orang lain sebagai orang yang memiliki kewenangan atas dirinya dan, apabila berada pada situasi yang tidak sesuai dengan konsep dirinya, maka akan muncul reaksi yang buruk yaitu kebencian dan perlawanan. Kondisi tersebut di atas melatar belakangi perilaku mahasiswa. Menurut Knowles (hal.45), "They have largely resolved their identity-formation issues; they are identified with an adult role. Any experience that they perceive as putting them in the position of being treated as children is bound to interfere with their learning".

Asumsi yang kedua menyatakan bahwa sebagai pribadi yang dewasa, "...he accumulates an expanding reservoir of experience that causes him to become an increasingly rich resource for learning, and at the same time provides him with a broadening base to which to relate new learnings" (hal.45). mengacu pada hal tersebut, maka peran guru dalam mengajar antara lain adalah pengemasan presentasi audio-visual, dan memberikan referensi bacaan untuk mendukung diskusi, praktek di laboratorium, simulasi, pengalaman lapangan, team project, serta teknik-teknik tindakan pembelajaran lainnya. Optimalisasi pengalaman mahasiswa dalam belajar merupakan suatu keharusan karena apabila mengabaikan pengalamannya akan diartikan pula pengabaian dirinya sebagai pribadi.

Asumsi yang ketiga menyatakan bahwa seorang yang dewasa, kesiapan belajarnya akan menurunkan produk perkembangan biologisnya dan tekanan akademis serta meningkatkan produk tugas-tugas perkembangannya yang diminta bagi kinerja pengembangan peran sosialnya. Artinya, "learners are ready to learn those things they "need" to because of the developmental phases they are approaching in their roles as workers, spouses, parents, organizational members and leaders, leisure time users, and the like.."(hal.47). Implikasinya adalah pentingnya pemilihan waktu untuk menyesuaikan (bertepatan) pelaksanaan pengalaman pembelajaran dengan tugas-tugas perkembangan para mahasiswa. Dalam pengamatannya, "... a good deal of professional education is totally out of phase with the students' readiness to learn".

Asumsi yang keempat mengatakan bahwa anak-anak telah dikondisikan untuk mencapai tujuan mata pelajaran dalam setiap pembelajaran, sedangkan orang dewasa cenderung untuk mampu memecahkan masalah dalam setiap pembelajarannya. Perbedaan inilah yang menjadi dasar adanya perbedaan hasil dalam perspektif waktu. Dalam perspektif waktu pembelajaran anak-anak, bahwa mata pelajaran yang dipelajari di sekolah dasar adalah memiliki pengaruh fungsi yang sedikit bagi persiapan yang lebih baik menjelang dewasa, tetapi sebagai persiapan untuk belajar lebih baik di tingkat lanjutnya serta berlangsung hingga sekolah menengah atas. Sementara, orang dewasa belajar hari ini agar bisa diterapkan pada hari esok. Asumsi ini memiliki dampak yang sangat besar terhadap organisasi kurikulum dan pengalaman pembelajarannya.

Dalam pendidikan orang dewasa, terdapat dua puluh prinsip yang dapat digunakan yang berasal dari tiga rumpun teori belajar yaitu Stimulus-Response Theory, Cognitive Theory, dan Motivation and Personality Theory. Berikut dalam tabel di bawah ini prinsip-prinsip pengajaran yang dapat digunakan bagi pendidikan orang dewasa: 


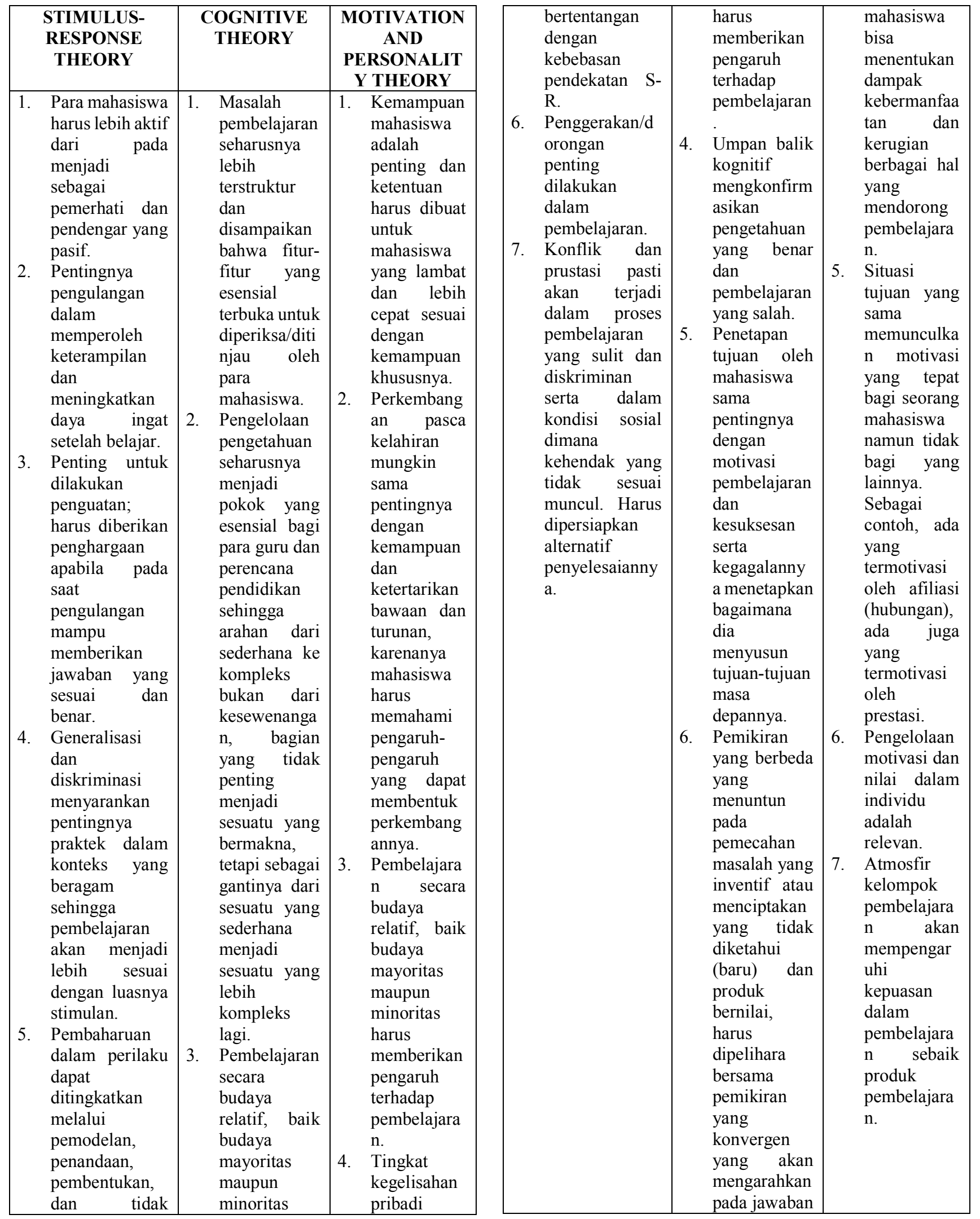




\begin{tabular}{|l|l|l|}
\hline & $\begin{array}{l}\text { yang benar } \\
\text { secara logika. }\end{array}$ & \\
\hline
\end{tabular}

Dalam pandangan konstruktivisme, para mahasiswa memainkan peranan yang aktif dalam 'membangun' pemahaman mereka sendiri. Pengetahuan tidak dapat dipandang sebagai sesuatu yang tetap dan berada bebas di luar para mahasiswa. Peters, Cornu, dan Collins (2003) mengatakan bahwa pemebelajaran merupakan suatu proses akomodasi atau adaptasi berdasarkan pada pengalaman baru atau ide-ide. Pendekatan konstruktivist menuntut para mahasiswa untuk menjadi aktif dan percaya terhadap diri dan kemampuan sendiri. Dukungan dosen dalam pembelajaran menjadi sangat penting untuk membantu para mahasiswa mengkonstruk pengetahuan yang dikembangkannya. Bruner (1996) mengatakan bahwa "The teacher's skill in establishing learning conversations with and amongst students is also fundamental to the construction of knowledge". Pernyataan tersebut ditegaskan pula oleh Peters, Cornu, dan Collins (2003) bahwa "learning conversations allow students and teachers to identify prior learning and exploit the difference between what is already known and what might be constructed as new knowledge". Dengan demikian tugas-tugas pembelajaran seharusnya menjadi student-centered atau setidaknya memberikan peluang bagi para mahasiswa menentukan pilihan.

\section{TANTANGAN PEMBELAJARAN}

Perkembangan Teknologi Informasi dan Komunikasi (ICT) telah meningkatkan level kompetensi untuk mencapai kesuksesan di era ekonomi berbasis pengetahuan seperti saat ini. Perubahan yang global dengan liberalisasi pendidikan telah menuntut lembaga pendidikan untuk mampu menghasilkan kualitas peserta didik yang dapat bersaing secara kompetitif agar dapat diterima pasar. Tuntutan untuk memenuhi kebutuhan pasar ini pada akhirnya akan mendorong lembaga pendidikan kita menjadi lebih bercirikan knowledge based economy institution. Punie, Zinnbauer and Cabrera (2006) mengatakan, "There is evidence that educational achievements are positively influenced by ICT'. Dan, terdapat bukti bahwa prestasi pendidikan dipengaruhi secara positif oleh ICT (TIK). Namun, temuan tersebut menyatakan bukan hanya TIK yang ada di sekolah tetapi termasuk juga TIK yang didapatkan para peserta didik yang ada di luar sekolah.

Implikasi dari era ekonomi berbasis pengetahuan adalah adanya kecenderungan peningkatan layanan untuk produk-produk jasa dan informasi, industri inovatif, pekerja yang terdidik yang memiliki kemampuan untuk menanggapi permasalahan kompleks secara fleksibel, berkomunikasi secara efektif, kemampuan mengelola informasi, mampu bekerja dalam tim, menghasilkan pengetahuan yang baru serta tuntutantuntutan terhadap penguasaan kompetensi yang berketerampilan tinggi (advanced skills). Implikasi ini membutuhkan kebijakan kreatif dalam penyelenggaran pendidikan dan pengembangan proses pembelajarannya agar menghasilkan capaian pembelajaran sebagaimana yang diharapkan. Pope (2005) mendefinisikan kreativitas sebagai "the application of knowledge and skills in new ways to achieve a valued goal', dimana, menurutnya terdapat empat kunci kualitas kreatifitas yaitu:

1. the ability to identify new problems, rather than depending on others to define them;

2. the ability to transfer knowledge gained in one context to another in order to solve a problem;

3. a belief in learning as an incremental process, in which repeated attempts will eventually lead to success; and

4. the capacity to focus attention in the pursuit of a goal or set of goals

Berkaitan dengan kebijakan tersebut di atas, Hargreaves, Lieberman, Fullan, dan Hopkins (2010) mencatat beberapa tema dalam fokus kebijakan pendidikan nasional di beberapa negara, antara lain:

1. standards-based measures to improve attainment in essential outcomes, especially numeracy and literacy;

2. reporting, assessment and accountability based on key performance indicators;

3. increasing post-compulsory participation by expanding higher education and creating new schoolwork pathways and higher vocational qualifications;

4. reshaping the educational workforce to emphasise flexibility, professional development, specialisation of professional and praprofessional roles and performance management;

Dari berbagai tema fokus kebijakan pendidikan tersebut di atas, dapat dimaknai bahwa berbagai negara telah menyiapkan bangsanya untuk siap bersaing secara terbuka di era ekonomi berbasis pengetahuan ini.

\section{PARADIGMA DALAM PENDIDIKAN: PARADIGMA PENGAJARAN DAN PEMBELAJARAN}

Sebagai implikasi dari globalisasi dan reformasi tersebut, terjadi perubahan pada paradigma pendidikan. Perubahan tersebut menyangkut empat hal (BSNP, 2010). Pertama, paradigma proses pendidikan yang berorientasi pada pengajaran dimana guru lebih menjadi pusat informasi, bergeser pada proses pendidikan yang berorientasi pada pembelajaran dimana peserta didik menjadi sumber (student center). Dengan banyaknya sumber belajar alternatif yang bisa menggantikan fungsi dan peran guru, peran guru berubah menjadi fasilitator. Kedua, paradigma proses pendidikan tradisional yang berorientasi pada pendekatan klasikal dan format di dalam kelas, bergeser ke model pembelajaran yang lebih fleksibel, seperti pendidikan dengan sistem jarak jauh. Ketiga, mutu pendidikan menjadi prioritas (berarti kualitas menjadi internasional). Keempat, semakin populernya pendidikan seumur hidup dan makin mencairnya batas antara pendidikan di sekolah dan di luar sekolah.

Mengacu pada paradigma pengajaran dan pembelajaran sebagaimana tersebut di atas, paradigma pengajaran lebih memfokuskan pada peningkatan kuantitas informasi, sedangkan paradigma pembelajaran fokus pada efisiensi dan efektifitas proses pembelajaran mengenai apa yang diketahui oleh peserta didik dan apa yang mampu mereka lakukan terhadap informasi baru (Arendale). Pergeseran ini menuntut para pengajar untuk belajar dan menemukan kembali 
sebagai sumber daya serta lingkungan pembelajaran yang terbarukan yang diharapkan dan dibutuhkan oleh dunia kampus beserta para mahasiswanya. Tuntutan ini mengarahkan para pengajar untuk mengintegrasikan diri dengan komunitas akademis dan mahasiswa sebagai sumber pembelajaran.

Berkaitan dengan kondisi tersebut di atas, Barr dan Tagg (1995) mengatakan bahwa pergeseran paradigma ini menjadikan kampus sebagai lembaga yang hadir untuk menghasilkan pembelajaran. Pergeseran ini membebaskan lembaga dari berbagai rangkaian kesulitan yang berkaitan dengan penyelenggaraan pengajaran karena misi lembaga adalah menghasilkan pembelajaran yang diikuti oleh seluruh mahasiswa melalui upaya-upaya terbaik dari mereka. Paradigma pembelajaran memberikan kesempatan pada para mahasiswa untuk menetapkan batas-batas pembelajaran dan keberhasilannya, sedangkan paradigma pengajaran berupaya mencapai keberhasilan atas apa yang telah ditetapkan lembaga dengan mengembangkan metode pengajaran tertentu.

Miller (2006) menegaskan bahwa "Learning was clearly the responsibility of the student, and its measurement was not a high priority". Pendapat tersebut dapat dimaknai bahwa pembelajaran menjadi lebih bersifat pribadi atau dikenal dengan istilah "Personalized Learning" (Johnson, Becker, Estrada and Freeman, 2015:26). Menurutnya, "Personalized learning refers to the range of educational programs, learning experiences, instructional approaches, and academic-support strategies intended to address the specific learning needs, interests, aspirations, or cultural backgrounds of individual students". Kondisi ini merupakan tantangan yang sangat sulit karena "the goal of personalized learning is to enable students to determine the strategy and pace at which they learn". Para peneliti pendidikan telah menekankan tentang perlunya pengaturan bagi landasan pembelajaran pribadi yang adaptif dan fleksibel. Kebutuhan dan dukungan belajar para peserta didik harus mampu difahami secara tepat sebelum merancang, mengembangakan dan mengimplementasikan pembelajaran.

\section{E. PERGESERAN PARADIGMA PEMBELAJARAN}

Dalam BSNP (2010), terdapat beberapa hal yang mencirikan adanya pergeseran paradigma pembelajaran, antara lain pandangan pembelajaran dari berpusat pada guru menuju berpusat pada siswa, dari satu arah menuju interaktif, dari isolasi menuju lingkungan jejaring, dari pasif menuju aktifmenyelidiki, dari abstrak menuju konteks dunia nyata, dari pribadi menuju pembelajaran berbasis tim, dari luas menuju perilaku khas memberdayakan kaidah keterikatan, dari stimulasi rasa tunggal menuju stimulasi ke segala penjuru, dari monomedia menuju multimedia, dari hubungan satu arah bergeser menuju kooperatif, dari produksi massa menuju kebutuhan pelanggan, dari usaha sadar tunggal menuju jamak, dari satu ilmu pengetahuan bergeser menuju pengetahuan disiplin jamak, dari kontrol terpusat menuju otonomi dan kepercayaan, dari pemikiran faktual menuju kritis, serta dari penyampaian pengetahuan menuju pertukaran pengetahuan.

Nichols (2013) menjelaskan tentang empat prinsip pembelajaran abad ke-21. Yaitu, instruction should be studentcentered (pembelajaran berpusat pada siswa); education should be collaborative (pendidikan yang kolaboratif); learning should have context (pembelajaran yang kontekstual); dan schools should be integrated with society (integrasi sosial). Pengembangan pembelajaran seyogyanya menggunakan pendekatan pembelajaran yang berpusat pada peserta didik. Peserta didik ditempatkan sebagai subyek pembelajaran yang secara aktif mengembangkan minat dan potensi yang dimilikinya. Mereka tidak lagi dituntut untuk mendengarkan dan menghafal materi, tetapi berupaya mengkonstruksi pengetahuan dan keterampilannya, sesuai dengan kapasitas dan tingkat perkembangan berfikirnya, sambil diajak berkontribusi untuk memecahkan masalah-masalah nyata yang terjadi di masyarakat. Pembelajaran berpusat pada peserta didik bukan berarti menyerahkan kendali belajar spenuhnya kepada peserta didik. Intervensi masih diperlukan dan pendidik berperan sebagai fasilitator yang berupaya membantu mengaitkan pengetahuan awal (prior knowledge) yang telah dimiliki peserta didik dengan informasi baru yang akan dipelajarinya. Memberi kesempatan pada peserta didik untuk belajar sesuai dengan cara dan gaya belajarnya masing-masing dan mendorong mereka untuk bertanggung jawab atas proses belajar yang dilakukannya. Selain itu, pendidik juga berperan sebagai pembimbing, yang berupaya membantu peserta didik ketika menemukan kesulitan dalam proses mengkonstruksi pengetahuan dan keterampilannya.

Peserta didik harus dibelajarkan untuk bisa berkolaborasi dengan orang lain. Berkolaborasi dengan orangorang yang berbeda dalam latar budaya dan nilai-nilai yang dianutnya. Dalam menggali informasi dan membangun makna, peserta didik perlu didorong untuk bisa berkolaborasi dengan teman-teman di kelasnya. Dalam mengerjakan suatu proyek, peserta didik perlu dibelajarkan bagaimana menghargai kekuatan dan talenta setiap orang serta bagaimana mengambil peran dan menyesuaikan diri secara tepat dengan mereka. Begitu juga, kampus (termasuk di dalamnya pendidik) seyogyanya dapat bekerja sama dengan lembaga pendidikan lainnya di berbagai belahan dunia untuk saling berbagi informasi dan penglaman tentang praktik dan metode pembelajaran yang telah dikembangkannya. Kemudian, mereka bersedia melakukan perubahan metode pembelajarannya agar menjadi lebih baik.

Pembelajaran tidak akan banyak berarti jika tidak memberi dampak terhadap kehidupan peserta didik di luar kampus. Oleh karena itu, materi kajian perlu dikaitkan dengan kehidupan sehari-hari peserta didik. Pendidik mengembangkan metode pembelajaran yang memungkinkan peserta didik terhubung dengan dunia nyata (real word). pengajar membantu peserta didik agar dapat menemukan nilai, makna dan keyakinan atas apa yang sedang dipelajarinya serta dapat mengaplikasikan dalam kehidupan sehari-harinya. Pendidik melakukan penilaian kinerja peserta didik yang dikaitkan dengan dunia nyata.

Dalam upaya mempersiapkan peserta didik menjadi warga negara yang bertanggung jawab, kampus seyogyanya dapat memfasilitasi peserta didik untuk terlibat dalam lingkungan sosialnya. Antara lain, adanya kegiatan pengabdian masyarakat. Peserta didik dapat dilibatkan dalam berbagai 
pengembangan program yang ada di masyarakat, seperti: program kesehatan, pendidikan, lingkungan hidup, dan sebagainya. Dengan kekuatan teknologi dan internet, peserta didik saat ini bisa berbuat lebih banyak lagi. Ruang gerak sosial siswa tidak lagi hanya di sekitar kampus atau tempat tinggalnya, tapi dapat menjangkau lapisan masyarakat yang ada di berbagai belahan dunia. Pendidikan perlu membantu peserta didik menjadi warga digital yang bertanggung jawab.

\section{F. PEMBELAJARAN YANG BERPUSAT PADA PESERTA $D I D I K$}

Pembelajaran yang berpusat pada peserta didik merupakan suatu cara pandang dalam upaya meningkatkan fokus tujuan penyelenggaraan kegiatan pengajaran dan pembelajaran. Terdapat dua istilah yang berbeda digunakan untuk menyampaikan pandangan dalam pembelajaran yang berpusat pada peserta didik, namun memiliki tujuan yang sama, yaitu Student Centered Teaching dan Student Centered Learning. Kecenderungan perbedaan penggunaan istilah untuk paradigma ini adalah Student Centered Teaching tergambarkan pada pendidikan sekolah menengah dan dasar, sedang Student Centered Learning dilakukan di pendidikan tinggi.

Wohlfarth (2008) mengatakan bahwa "The learnercentered paradigm departs from traditional teaching models by focusing on students more than teachers and learning more than teaching". Menurutnya, Student Centered Teaching merupakan suatu perubahan paradigma model pengajaran tradisional melalui peningkatan fokus pada pseserta didik dari pada para guru dan pembelajaran dari pada pengajaran. Dan, dengan paradigma tersebut kelas akan menjadi lebih egaliter, para peserta didik lebih menekankan pada pemikiran kritis, pembelajaran aktif, serta tugas-tugas lebih mengacu pada realitas kehidupan.

Student Centered Teaching menuntut hubungan antara pengetahuan dengan peserta didik harus pada saat yang bersamaan. Weimer (2002) menyebutkan perubahan-perubahan yang terjadi ketika pembelajaran berpusat pada peserta didik, yaitu the balance of power, the function of content, the role of teacher, the responsibility of learning, the purpose and processes of evaluation. Dan, terdapat tiga hal yang dilakukan dalam mengimplementasikan pendekatan ini, yaitu responding to resistance, taking a developmental approach, dan making learner centered teaching work.

EI dan ESU (2010) menganggap bahwa konsep Student Centered Learning (SCL) telah dikembangkan oleh Hayward (1950), dalam karya John Dewey (1956), Carl Rogers dengan Theory of Education (1980), karya Piaget (Developmental Learning), dan karya Malcolm Knowles (selfdirected Learning). Secara umum SCL berlandaskan pada aliran konstruktivisme sebagai suatu teori pembelajaran yang dibangun dengan ide bahwa pembelajar (peserta didik/mahasiswa) harus mengkonstruksi dan mengkonstruksi kembali pengetahuan agar dapat belajar secara efektif, dengan pembelajaran yang lebih efektif pada saat mahasiswa sebagai bagian dari kegiatan pembelajaran melalui pengalamannya dapat mengkonstruksi suatu produk yang sangat bermakna. SCL juga dianggap sama dengan pembelajaran transformatif yang melihat suatu proses perubahan kualitatif pada pembelajar sebagai suatu proses transformasi yang berjalan dengan fokus meningkatkan dan memberdayakan peserta didik/mahasiswa serta membangun kemampuan kritisnya.

Dalam berbagai sumber, terdapat beberapa elemen dalam konsep SCL, antara lain ketergantungan pada pembelajaran aktif dibandingkan dengan pembelajaran pasif, menekankan pada pembelajaran yang mendalam dan pemahaman, responsibilitas dan akuntabilitas mahasiswa harus lebih ditingkatkan, ditingkatkan pula sense of autonomy pada mahasiswa, adanya saling ketergantungan antara dosen dan mahasiswa, saling menghormati dalam hubungan dosen dengan mahasiswa, serta pendekatan reflektif bagi proses pengajaran dan pembelajaran, baik bagi dosen maupun mahasiswa. Menurut Napoli (2004), “... as teachers, we should avoid seeing 'student-centred learning' as a 'quality' imposition on the part of governments and institutions, as it should really be at the centre of our preoccupations as educators". Bagi para dosen, jika dilakukan dengan benar dan dengan upaya kolektif antara kelompok, pembelajaran yang berpusat pada siswa dapat menjadi salah satu cara untuk mempersiapkan kembali profesionalisme kita sendiri dalam menghadapi kecepatan perubahan yang terjadi.

\section{G. PENUTUP}

Sebagai upaya pemberdayaan sumber daya manusia dan peningkatan produktifitas yang dilakukan, khususnya pendidikan tinggi, dibutuhkan cara pandang baru untuk melakukan perubahan kegiatan pembelarajan untuk dapat mencapai tujuan pendidikan secara efektif. Pendiidkan tinggi harus mampu menyediakan dan menghasilkan pembelajaranpembelajaran yang baru dan lebih produktif serta berdaya saing.

Dalam implementasinya, pembelajaran pada pendidikan tinggi dapat menggunakan berbagai teori-teori pembelajaran yang mendukun, antara lain Stimulus-Response Theory, Cognitive Theory, Motivation and Personality Theory, dan Constructive Theory. Prinsip-prinsip dari teori tersebut dapat memberikan panduan pelaksanaan pembelajaran, dimana orang dewasa sebagai objeknya. Melalui teori-teori tersebut juga pembelajaran yang efektif dan efisien dapat dicapai dalam upaya mewujudkan tujuan pendidikan.

Persaingan dalam globalisasi memunculkan suatu era baru yaitu era ekonomi berbasis pengetahuan yang mensyaratkan kreativitas, inovasi, kompetensi dan daya saing. Hal ini menjadi tantangan bagi dunia pendidikan dalam mengahsilkan lulusannya. Keterbukaan dan kecepatan akses informasi menjadi bagian yang tidak terpisahkan dalam lingkungan pendidikan. Semua tantangan tersebut harus terintegrasi pada satu sosok manusia modern yang dapat dihasilkan oleh perguruan tinggi sebagai lembaga pendidikan formal pada level akhir. Tantangan ini perlu disikapi dengan langkah awal melakukan perubahan paradigma dalam pembelajaran.

Perubahan paradigma pembelajaran terjadi dari paradigma berfokus pada guru/dosen menjadi pembelajaran berfokus pada peserta didik atau mahasiswa. Pada pendidikan tinggi dikenal Student-Centered Learning sebagai pembelajaran 
yang berfokus pada mahasiswa. Keterpaduan lembaga pendidikan dalam menghasilkan pembelajaran yang berkualitas yang dilakukan oleh dosen dan mahasiswa menjadi bentuk yang utuh dalam pendekatan ini. Lembaga pendidikan dengan visi, misi dan tujuannya bersinerji dalam kurikulum yang dikembangkan dengan dosen dan mahasiswanya. StudentCentered Learning, dalam berbagai kajian yang telah dilakukan, dipandang dapat meningkatkan efektivitas pencapaian tujuan pendidikan.

\section{REFERENSI}

Altbach, Philip G. 2001. Academic freedom: International realities and challenges. Kluwer Academic Publishers. Printed in the Netherlands. Center for International Higher Education, Campion Hall, Boston College, Chestnut Hill, MA 02467, U.S.A. (E-mail: altbach@bc.edu)).

2010. Global Competence Is a 21st Century Imperative. NEA Education Policy and Practice Department. Center for Great Public Schools 1201 16th St., NW, Washington, D.C. 20036.

www.nea.org/assets/docs/HE/PB28A_Global_Competence1 $1 . \mathrm{pdf}$

Mansilla, Veronica Boix \& Jackson, Anthony. 2011. Educating for Global Competence: Preparing Our Youth to Engage The World. Council of Chief State School Officers' EdSteps Initiative \& Asia Society Partnership for Global Learning. Asia Society 725 Park Avenue New York, NY 10021 voice: 212-288-6400 . fax: 212-517-8315 www.asiasociety.org/education

. 2013. High Level Group on the Modernisation of Higher Education. Report to the European Commission on Improving the quality of teaching and learning in Europe's higher education institutions. ec.europa.eu/education/library/reports/modernisation_en.pd f

Punie, Yves., Zinnbauer, Dieter., and Cabrera, Marcelino. (2006). A Review of the Impact of ICT on Learning. Working Paper prepared for DG EAC, October 2006. JRC Technical Notes. JRC European Commission and Institute for Prospective Technological Studies (IPTS).

Peters, Judi., Cornu, Rosie Le., Collins, Janet. (2003). Towards Constructivist Teaching and Learning: A Report on Research Conducted in Conjunction with the Learning to Learn Project, November 2003. www.learningtolearn.sa.edu.au/tfel/files/.../learning_to_lear $\mathrm{n}$ report.doc

.2008. $21^{\text {st }}$ century skills, education and competitiveness. A Resource and Policy Guide. Partnership for $21^{\text {st }}$ Skills. www.21stcenturyskills.org

Pope, Rob. 2005. Creativity - Theory, History, Practice. by Routledge. 2 Park Square, Milton Park, Abingdon, Oxon, OX14 4RN

Andy Hargreaves, Ann Lieberman, Michael Fullan, David Hopkins. 2010. Second International Handbook of Educational Change, Part I. Springer International Handbooks of Education. Volume 32. ISBN 978-90-481-2659-0. DOI 10.1007/978-90-481-2660-6. Springer Dordrecht Heidelberg London New York. Library of Congress Control Number: 2010927490. http://www.springer.com/series/6189
Barr R. B and Tagg J, 1995. FROM LEARNING TO TEACHING - A New Paradigm for Undergraduate Education. Magazine of Higher Learning. Volume 27, Issue 6, 1995

Bruner, J. (1996) The Culture of Education, London, Harvard University Press.

EI, ESU. (2010). Student-Centred Learning. An Insight into Theory and Practice. (Brussels, Education International, European Students' Union).

Miller Herman. 2006. PARADIGM SHIFT - How Higher Education is Improving Learning. https://www.hermanmiller.com/content/dam/hermanmiller/ documents/research_summaries/wp_LearningParadigm.pdf

Gordon, Gordon, Aber and Berliner. . CHANGING PARADIGMS FOR EDUCATION. The Gordon Commission on the Future of Assessment in Education http://www.gordoncommission.org

Arendale, David. Leading the Paradigm Shift from Teaching to Learning. a.web.umkc.edu/arendaled/paradigm98.pdf

Phenix, Philip H. 1986. Realms of Meaning. A Philosophy of The Curriculum for General Education. A Perspective Through a Retrospevtive Volume 8. Ventura County Superintendent of Schools Office. Ventura, California. Printcraft Inc. 2004. Karya KI HADJAR DEWANTARA. Bagian Pertama: Pendidikan. Cetakan ketiga. Diterbitkan oleh Majelis luhur Persatuan Taman Siswa Yogyakarta - 55151

1998. Lifelong Learning and Institutions of Higher Education in The $21^{\text {st }}$ Century. Report on the Preparatory Meeting for the World Conference on Higher Education. Published by Department of Adult and Continuing Education and Extention, University of Mumbai, Mumbai, India And UNESCO Institute for education Hamburg, Germany.

Jarvis, Peter. 2001. Universities as Institutions of Lifelong Learning: Epistemological Dilemmas. Journal of Higher Education Outreach and Engagement, Volume 6, Number 3, p. 23.

Johnson, L., Adams Becker, S., Estrada, V., and Freeman, A. (2015). NMC Horizon Report: 2015 Higher Education Edition. Austin, Texas: The New Media Consortium.

Knowles, Malcolm. (1973). The Adult Learner: A Neglected Species. American Society for Training and Development, Madison, Wis. Gulf Publishing Company, P.O. Box 2608, Houston, TX 77001

Tapscott, Don. (2009). Grown Up Digital: How the Net Generation is Changing Your World. McGraw-Hill eBooks. ISBN: 9780-07-164155-5. MHID: 0-07-164155-6

Nichols, Jennifer R. (2013). 4 Essential of 21st Century Learning. http://www.teachthought.com/learning/4-essential-rules-of21st-century-learning/

Wohlfarth, DeDe \& asc. 2008. Student Perceptions of LearnerCentered Teaching. Insight: A Journal of Scholarly Teaching. Volume $3-2008$.

Weimer, Maryellen. 2002. Learner-Centered Teaching. Five Keys Changes to Practice. Jossey-Bass. A Wiley Company. San Francisco.

Napoli, Roberto Di. 2004. What is Student Centered Learning? Educational initiative Centre. Elearning@bath. http://www.bath.ac.uk/e-learning/student centredness.htm 